Here are various reasons for the encouragement of research : the benefit of the student, the addition to human knowledge, power and riches, and the needs of defence, military and industrial. But I think we still have failed to include the most important reason of all, the real reason of which the others are only derivatives. It is that the spirit of research is like the movement of running water, and the absence of it like the stagnation of a pool. Scientific research, in its widest sense, implies, of course, far more than exploring the questions of physics and chemistry and biology. It is not a religion; but it is the act of one. It is the outcome of a belief that in all things which we try to do we may by careful seeking and by a better understanding do them better; that the world, far beyond what we can see of it on the surface, is full of things which it would be well for us to know. It is our duty and our gain to explore: we have always grown by doing so, and we believe that the health of our souls depends on doing so. Shall we sit still when there are difficult questions to solve; and when the answers may give us new insight and new power? There is a hesitation which would beg us not to push forward lest we come to think less of the world. As against this, research is an act of faith in the immensity of things. There is no end to the search : it is a poor thought that there might be.

The spirit of research would drive us all to work to the utmost of our power, believing that the more we do and the better we do it, the better for the work and lives of others. It is vigorous, hopeful, trustful and friendly; it adds always new interest and new life. It is a spirit which should run through all our activities, and not be found in laboratories only. It is, in fact, a spirit which is essential to us as a nation trying to rise above ourselves to better things. All our efforts to encourage research have before them not only one or other such immediate object like that to which I have already referred, but also this great ideal.

\title{
Lightning and High-Voltage Phenomena.
}

$\mathrm{M}$ ANY estimates have been made of the voltage required to produce a lightning flash. It is now possible to give a rough estimate. The very high pressures at present used in the everyday transmission of electric power by engineers have led to researches in high-voltage phenomena, and results have been obtained which prove that the average voltage before a lightning flash occurs is of the order of roo million volts. The General Electric Co. of America has built a million-volt ( $\mathrm{r} \cdot 4$ million maximum) transformer for testing the strings of insulators which are used to suspend the power lines in California where the pressures between neighbouring wires are 220,000 volts. It is also necessary to test the lightning protective devices used, and so a twomillion-volt "impulse" generator has been built for this purpose.

Mr. F. W. Peek, the consulting and research engineer of the General Electric Co., describes in the January number of the Journal of the Franklin Institute some interesting experiments he has made with these machines and deduces important results. He finds that up to two million volts, the maximum highest voltage obtained, the ordinary formulæ for the sparking distances between spherical electrodes are true. Consequently, with very large electrodes at considerable distances apart, an average voltage of $r_{50,000}$ per foot is required to produce a spark. Estimates of the voltage required for a lightning flash can therefore reasonably be made.

Mr. Peek has found that the laws for disruptive discharge between needle gaps, between spherical electrodes and for visual coronas found at low voltages, still apply at high voltages. He proves experimentally that the curve connecting the disruptive voltage for a needle gap with its length is a straight line at least up to two million volts. The curve for a spherical electrode gap is in accordance with the assumption that the disruptive discharge takes place when the maximum value of the potential gradient in the gap attains a definite well-known value depending on the size of the spheres. It was found by experiment that the "impulse" spark-over voltage of the needle gap varies

$$
\text { NO. } 2835 \text {, VOL. I I } 3]
$$

with the wave shape of the impulse, but the sphere gap disruptive voltage is practically unaffected by the wave shape.

The experiments prove that the wet and dry sparkover voltages for strings of insulators are practically the same whatever the applied pressure. The voltages used in these experiments were of the same order as the "lightning voltages" which appear on power transmission lines. It is known that a definite amount of energy is required to rupture gaseous, liquid, and solid insulating materials. For example, when a voltage is applied at a very rapid rate, as by an impulse generator, breakdown does not occur at the same pressure as that required by a continuously applied voltage. In air with spherical electrodes the time lag is practically negligible, but with needle points it is easily measurable. Hence this can be used to measure the rapidity of the impulse.

Photographs are shown of a spark-over on a string of porcelain insulators protected by two large rings at each end. The discharge is seen taking place between the rings, the insulators being completely shielded. Lightning voltages cause coronas on the wires. It was found that a corona produced by a "lightning" voltage which lasted less than the millionth of a second could be easily seen. The fact that coronas are caused by these sudden voltages explains why lightning discharge rushes are so rapidly damped on transmission lines.

Mr. Peek calls lightning an "electrical explosion," and states that time periods of less than the millionth of a second are required for the discharge in model "lightning" generators in order to get trustworthy results. He uses a generator giving two million volts, and it sometimes produces a current of the order of ten thousand amperes. A photograph is shown of a large wooden post split and blown apart by the discharge. After the explosion the wood had the odour of the gases produced by destructive distillation, but there was no sign of burning. A plate of glass coated with metal was perforated at this pressure.

When lightning strikes the earth where the soil is 
sandy, its path through the sand is often defined by a long tube, which may have branches like a tree. These tubes, called fulgurites, are well known. It was found that they could easily be produced by artificial lightning.

Most of the disturbances caused on transmission lines are due to electrical induction and are not due to a direct flash striking the line. A neighbouring flash, however, can release the "bound" charge, which then travels over the line in each direction with a velocity comparable with that of light. As these lightning waves travel over the lines they are gradually dissipated by the losses which occur. The author has measured induced lightning voltages in transmission lines in Colorado as high as 500,000. From experiments with a model three-phase transmission line with a large plate to represent the cloud directly above it, he deduces that with a cloud 864 feet high and a transmission line 30 feet high, two out of every fifty flashes would strike the line, the remainder striking the earth.

Wooden logs can easily be set on fire by a spark from a lightning generator. This proves that there is a direct risk of fire. Tests are being carried out to determine the best methods of protecting buildings from lightning. Miniature buildings, clouds, etc., are being constructed accurately to scale. So far as the experiments have gone, they prove that lightning conductors have a real value in protecting buildings. Whether they increase the chance of a building protected by them being struck by lightning has still to be investigated. In an appendix the practical formulæ for sparking voltages between spheres and cylinders are given.

\section{Helium-filled Airships.}

$\mathrm{N}$ the whole history of science there is no more wonderful example of practical service arising out of purely scientific study than is afforded by the use of helium gas in airships. As readers of NATURE are well aware, the gas was first detected in solar promi- for aeronautical purposes, and two years later a similar investigation was carried out in the United States, where the gas is now produced in sufficient quantity to inflate large airships.

Three months ago we wrote to Rear-Admiral W. A.

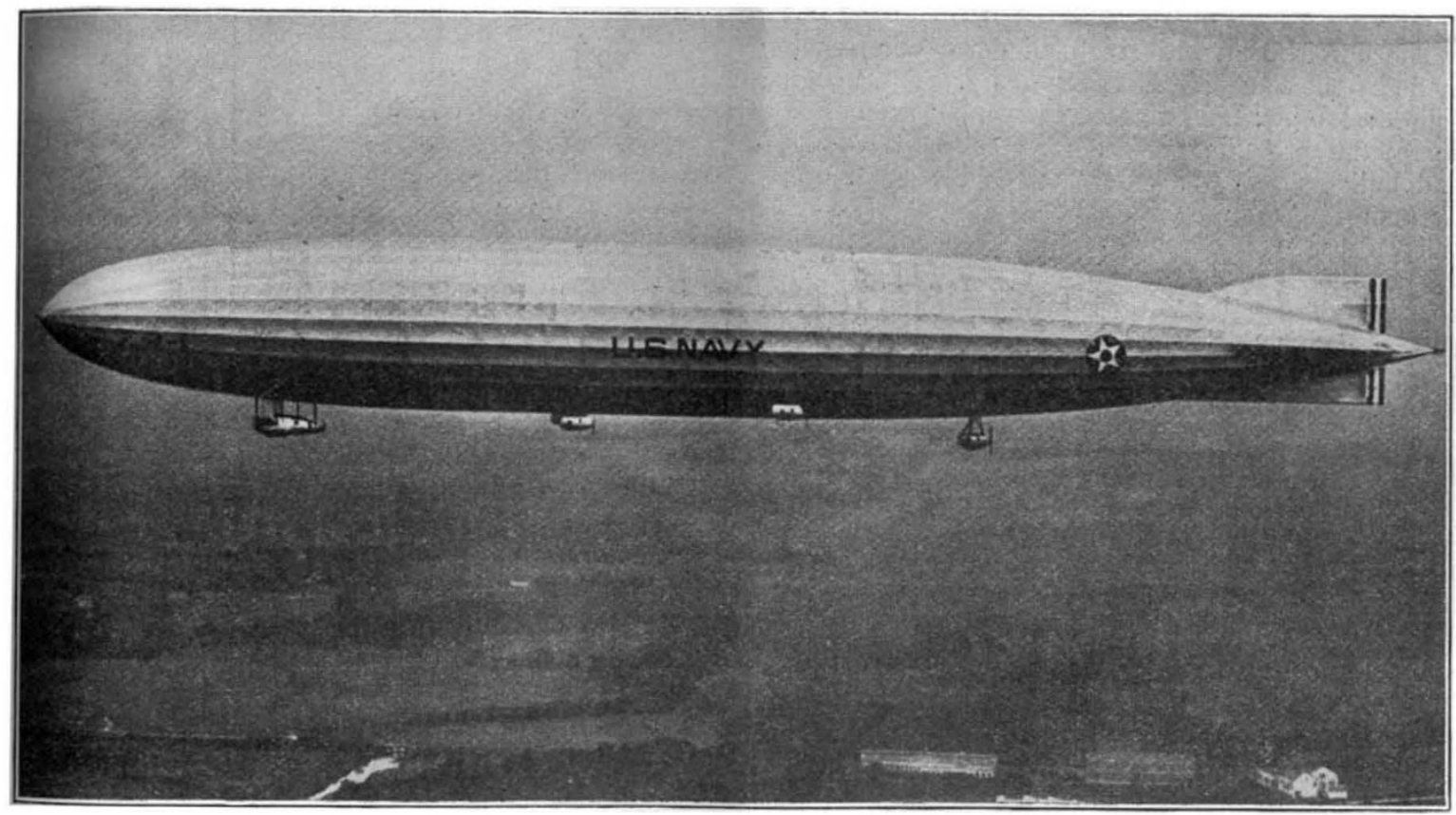

FIG. I.-The United States Navy ZR-r, now the U.S.S. Shenandoah.

Length, 680 feet; diameter, 78 feet; height, 96 feet; gas capacity, 2,150,000 cubic feet; total lift (helium), about 130,000 pounds; dead weight, about 75,000 pounds; speed, about 70 miles per hour; horse-power, six $300-\mathrm{H}$.P. engines, total $1800 \mathrm{H}$.P.; cruising radius without stopping, more than 4000 miles; crew, 9 officers, 22 enlisted men.

nences by Sir Norman Lockyer in 1868, and as he was unable then to identify it with a terrestrial element, "I took upon myself," he said, " the responsibility of coining the word helium." So the gas remained until 1895, when Sir William Ramsay obtained it from the mineral cleveite, and it has since been found in many types of rocks and minerals as well as in natural gases and spring-waters.

In the year I9I5 an inquiry was made into the helium content of natural gases within the British Empire from the point of view of their development
Moffett, chief of the Bureau of Aeronautics, U.S. Navy Department, Washington, D.C., for particulars of this interesting development, and he has been good enough to send us the following details, with a photograph here reproduced (Fig. r) of the large airship U.S.S. Shenandoah, which is inflated with helium. We are very glad to be able to publish this account.

The U.S.S. Shenandoah was authorised in I9I9, construction was begun in 1920, and the ship made her first flight in September 1923.

NO. 2835 , VOL. I I 3$]$ 